\title{
Heart failure management insights from primary care physicians and allied health care providers in Southwestern Ontario
}

\author{
Narlon C. Boa Sorte Silva ${ }^{1,2}$, Roseanne W. Pulford' ${ }^{1}$, Douglas S. Lee ${ }^{3,4}$ and Robert J. Petrella $1,2,5,6^{*}$
}

\begin{abstract}
Background: It remains to be determined whether collaborative strategies to improve and sustain overall health in patients with heart failure (HF) are currently being adopted by health care professionals. We surveyed primary care physicians, nurses and allied health care professionals in Southwestern Ontario regarding how they currently manage HF patients and how they perceive limitations, barriers and challenges in achieving optimal management in these patients.

Methods: We developed an online survey based on field expertise and a review of pertinent literature in HF management. We analyzed quantitative data collected via an online questionnaire powered by Qualtrics ${ }^{\oplus}$. The survey included 87 items, including multiple choice and free text questions. We collected participant demographic and educational background, and information relating to general clinical practice and specific to HF management. The survey was 25 min long and was administered in October and November of 2018.

Results: We included 118 health care professionals from network lists of affiliated physicians and clinics of the department of Family Medicine at Western University; $88.1 \%(n=104)$ were physicians while $11.9 \%(n=14)$ were identified as other health care professionals. Two-thirds of our respondents were females $(n=72)$ and nearly onethird were males $(n=38)$. The survey included mostly family physicians $(n=74)$ and family medicine residents $(n=$ 25). Most respondents indicated co-managing their HF patients with other health care professionals, including cardiologists and internists. The vast majority of respondents reported preferring to manage their HF patients as part of a team rather than alone. As well, the majority respondents $(n=47)$ indicated being satisfied with the way they currently manage their HF patients; however, some indicated that practice set up and communication resources, followed by experience and education relating to HF guidelines, current drug therapy and medical management were important barriers to optimal management of HF patients.
\end{abstract}

Conclusions: Most respondents indicated HF management was satisfactory, however, a minority did identify some areas for improvement (communication systems, work more collaborative as a team, education resources and access to specialists). Future research should consider these factors in developing strategies to enhance primary care involvement in co-management of $\mathrm{HF}$ patients, within collaborative and multidisciplinary systems of care.

Keywords: Heart failure management, Primary care, Health care professionals

\footnotetext{
* Correspondence: petrella@uwo.ca

${ }^{1}$ Centre for Studies in Family Medicine, Department of Family Medicine,

Schulich School of Medicine and Dentistry, Western University, London, ON,

Canada

${ }^{2}$ School of Kinesiology, Faculty of Health Sciences, Western University,

London, ON, Canada

Full list of author information is available at the end of the article
}

(c) The Author(s). 2020 Open Access This article is distributed under the terms of the Creative Commons Attribution 4.0 International License (http://creativecommons.org/licenses/by/4.0/), which permits unrestricted use, distribution, and

reproduction in any medium, provided you give appropriate credit to the original author(s) and the source, provide a link to the Creative Commons license, and indicate if changes were made. The Creative Commons Public Domain Dedication waiver (http://creativecommons.org/publicdomain/zero/1.0/) applies to the data made available in this article, unless otherwise stated. 


\section{Background}

Providing health care at a level of excellence to achieve and sustain improvements in patient health is the ultimate goal in clinical practice, this holds true particularly in patients diagnosed with heart failure (HF) [1]. Since HF is one of the main cardiovascular causes of death, it largely impacts the health care system, the patient's family, caregivers, and physicians [2]. Moreover, with increasing survival rates following heart attacks, the incidence of people living with HF is rising in Canada, reaching approximately 50, 000 newly diagnosed each year according to the Heart and Stroke Foundation of Canada [3]. Therefore, implementing strategies to identify and counter-act limitations, barriers and challenges in HF management in primary care is a primordial step towards enhancing overall quality of health care services for patients.

Many factors have been identified to negatively influence the health status of HF patients, and one of these factors is the readmission of patients to acute care $[4,5]$. It has been suggested that adoption of collaborative strategies among professionals (e.g., physicians, nurses, allied health and specialists) and institutions (hospitals and in-patient/out-patient clinics), as well as, implementation of post-discharge HF management programs, could result in lowering readmission rates in HF patients, and possibly lead to long-term, sustained health status $[4,6]$. Furthermore, early collaborative care for HF patients, which could include collaboration between primary care physicians and specialist [2], seems to be particularly efficient in reducing mortality compared to primary care alone [2].

The current guidelines for the management of HF published by the Canadian Cardiovascular Society state that the management of these patients should be delivered within a system of care, following principles of chronic disease management and prevention [7]. However, it remains to be determined whether such strategies are currently being adopted by health care professionals. Therefore, the aim of this study was to investigate how health care professionals (e.g., family doctors, specialists, residents, nurses) from Southwestern Ontario manage HF patients, and identify the perceived limitations, barriers and challenges in achieving optimal HF management of patients in primary care.

\section{Methods}

\section{Respondents}

We recruited respondents from community-based practices and teaching hospitals across Southwestern Ontario. More specifically, respondents were located in 20 cities (based on their postal codes) bounded by the cities of Windsor and Essex County in the West, Hanover in the North, Kitchener to the East, and Leamington to the
South (see Fig. 1). The online survey was sent to network listings of primary care and allied health professionals in practice or training from the Department of Family Medicine at Western University and included the following email networks: a) Clinical Academic Faculty and Adjunct Faculty in Family Medicine at Western University; b) Citywide Department of Family Medicine at Western University; c) Family Medicine Educational Research Networks at Western University; d) Family Medicine Residents at Western University; e) Amherstburg Family Health Team; f) North Perth Family Health Team; g) Stratford Family Health Network; and h) Peninsula Family Health Team. Email recipients were informed that their responses were anonymous and neither they themselves, their location nor their practice would be identified. In addition, recipients were informed that by answering the questionnaire they would be providing consent to participate.

\section{Survey development}

Our team developed this survey based on field expertise and a review of pertinent literature in HF management, and one of the team members (RWP) underwent specific professional training prior to building the survey via the Institute for Healthcare Improvement (Open School), Quality Improvement [8]. The content of the survey was first created in a paper format and underwent critical revision by the study principal investigator (RJP), after which the questions were transformed to an online version using Qualtrics Software (2019 Qualtrics ${ }^{\oplus}$, Provo, UT) in collaboration with Western University [9]. The survey included 87 items, including multiple choice and free text questions. All survey questions underwent pilot testing prior to release to participants. We collected participant demographic information and educational background, as well as information relating to general clinical practice and specific to HF management. The survey was approximately $25 \mathrm{~min}$ long and was administered in October and November of 2018.

\section{Data analysis}

In this report, we analyzed only quantitative data collected via our online questionnaire. Qualitative responses from a sub-sample of respondents will be reported separately. All data generated by multiple choice questions were analyzed using descriptive statistics and no inferential statistical tests were performed on the data. We summarized the data as either frequency and percentage, or median and interquartile range (IQR). Although we removed outliers from the data during preprocessing stages in the statistical analysis, we explored the data to a maximum extent and no single answers were excluded. We conducted all analyses using 


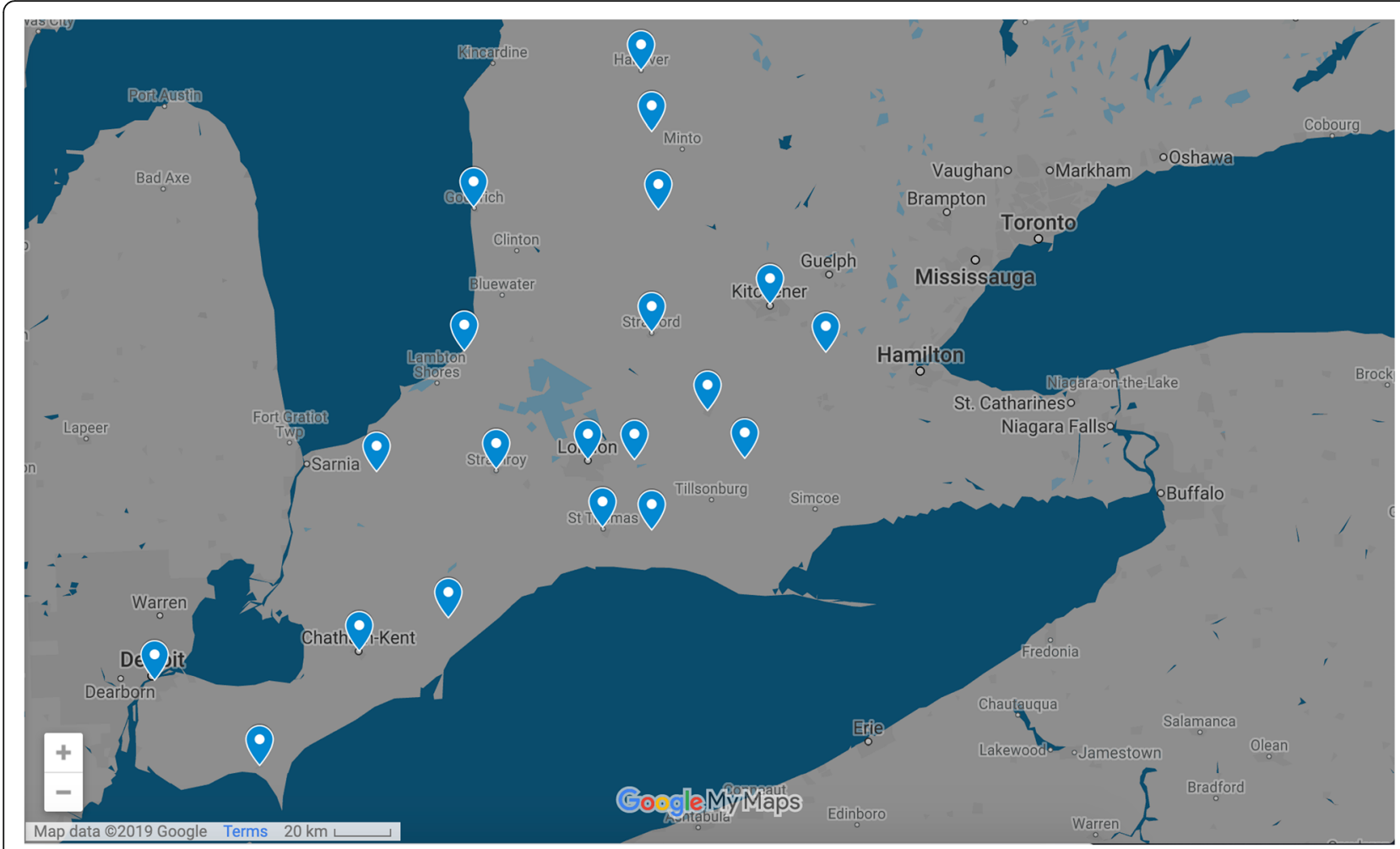

Fig. 1 Respondent locations in the Heart Failure Management Survey across Southwestern Ontario. Note: The locations identified in map are Aylmer, Branchton, Chatham, Clifford, Dorchester, Goderich, Grand Bend, Hanover, Highgate, Kitchener, Leamington, Listowel, London, Norwich, St. Thomas, Stratford, Strathroy-Caradoc, Windsor, Woodstock, and Wyoming. The figure was derived from Map data@2019 Google

IBM $^{\bullet}$ SPSS $^{\bullet}$ Statistics for Mac, Version 24.0 (Armonk, NY: IBM Corp.).

\section{Results}

\section{Demographic information}

This study included 118 health care professionals; $88.1 \%$ $(n=104)$ were physicians while $11.9 \%(n=14)$ were identified as other health care professionals. Two-thirds of our respondents were females $(n=72)$ and nearly one-third were males $(n=38)$. Family physicians $(n=74)$ and family medicine residents $(n=25)$ composed the first and second largest group of doctors in this survey, respectively. As well, one general internist (group practice) and four specialists (emergency $[n=1]$, geriatric medicine $[n=1]$, palliative care $[n=1]$, sport and exercise medicine $[n=1]$ ) were also surveyed. Among 14 other health care professionals, our sample included nurse practitioners, registered nurses, registered practical nurses, and others (registered dietitian and chronic disease team lead $[n=1]$, registered respiratory therapist $[n=1]$, and social worker $[n=1])$. Please see Table 1 for a description of our respondents.
Table 1 Demographic information

\begin{tabular}{lll}
\hline Category & $N$ & $\%^{\mathrm{a}}$ \\
\hline Sex & 72 & 61 \\
Female & 38 & 32.2 \\
Male & 3 & 2.5 \\
Other & & \\
Physicians & 74 & 62.7 \\
Family Physicians & 1 & .8 \\
General Internist (group practice) & 25 & 21.2 \\
Family Medicine Resident & 4 & 3.4 \\
Specialist & & \\
Other Health Care Professionals & \\
Nurse Practitioner & 6 & 5.1 \\
Registered Nurse & 3 & 2.5 \\
Registered Practical Nurse & 1 & .8 \\
Registered dietitian and chronic disease team lead & 1 & .8 \\
Registered respiratory therapist & 1 & .8 \\
Social worker & 1 & .8 \\
\hline
\end{tabular}

apercentage calculated from overall sample

bPlease note data missing for one participant regarding their professional affiliation 


\section{Educational background}

The vast majority of our respondents completed their undergraduate medical training in Canada $(n=85)$, whereas others receive their training in other countries $(n=26)$, mostly outside North America $(n=24)$. As well, most respondents received their degree between the decades of 2000 to $2009(n=27)$ and 2010 to 2019, $(n=$ $44)$. Moreover, more than two-thirds of respondents indicated receiving post-graduate medical training $(n=78)$, mostly in family medicine $(n=55)$, and mostly in Canada $(n=74)$ while 70 received Certification by the College of Family Physicians of Canada (CCFP). Please see Table 2 for detailed information.

\section{General clinical practice}

More than two-thirds of our respondents reported having hospital privileges $(n=76)$. Of those with hospital

Table 2 Educational background and current practice

\begin{tabular}{|c|c|c|}
\hline Category & $N$ & $\%^{\mathrm{a}}$ \\
\hline \multicolumn{3}{|l|}{ Education } \\
\hline \multicolumn{3}{|l|}{ Country of graduation } \\
\hline Canada & 85 & 72 \\
\hline USA & 2 & 1.7 \\
\hline Other Counties & 24 & 20.3 \\
\hline \multicolumn{3}{|l|}{ Year of graduation } \\
\hline 1970 to 1979 & 8 & 7.3 \\
\hline 1980 to 1989 & 14 & 12.7 \\
\hline 1990 to 1999 & 17 & 15.5 \\
\hline 2000 to 2019 & 27 & 24.5 \\
\hline 2010 to 2019 & 44 & 40.0 \\
\hline \multicolumn{3}{|l|}{ Post-graduate Medical Training ${ }^{b}$} \\
\hline Family Medicine & 55 & 46.2 \\
\hline Other & 29 & 24.3 \\
\hline No Post-graduate Medical Training & 43 & 36.1 \\
\hline \multicolumn{3}{|l|}{ Practice Location } \\
\hline Rural & 36 & 30.5 \\
\hline Urban & 78 & 66.1 \\
\hline \multicolumn{3}{|l|}{ Hospital Privileges } \\
\hline No & 38 & 32.2 \\
\hline Yes & 76 & 64.4 \\
\hline \multicolumn{3}{|l|}{ Type of Hospital Setting } \\
\hline Academic Health Sciences Centre (AHSC) & 41 & 34.7 \\
\hline Community hospital & 28 & 23.7 \\
\hline Emergency department (in community hospital or AHSC) & 2 & 1.7 \\
\hline Non-AHSC teaching hospital & 2 & 1.7 \\
\hline Other hospital & 1 & .8 \\
\hline
\end{tabular}

${ }^{\text {aPercentage calculated from overall sample }}$

${ }^{b}$ Eight respondents reported having other post-graduate medical training in addition to family medicine privileges, the vast majority reported having access to an Academic Health Sciences Centre $(n=41)$ or community hospital $(n=28)$. Five respondents indicated they practiced in solo practice, four of which indicated having a nurse available. With regards to their main practice location, one-third of respondents indicated practicing mainly in rural $(n=36)$, while the majority reported practicing in urban locations $(n=78)$. Please see Table 2 for detailed location information. In addition, survey respondents indicated seeing on average 70 patients (median, IQR = 50) on a weekly basis, with some respondents seeing as many as 220 patients per week. For urgent matters, our respondents $(n=83)$ reported that most patients would have a first available appointment for the same day; similarly, for non-urgent matters, respondents $(n=66)$ reported that patients are seen within the same week. Please see Table 3 for details.

We requested respondents to rate their access to different resources for treating HF patients; these are reported in Fig. 2. Briefly, most respondents reported satisfactory to excellent access to hospital in-patient care on an urgent basis, hospital care for elective procedures, and routine diagnosis services; however, there were more unsatisfactory to satisfactory ratings of access to advanced diagnosis services (e.g., magnetic resonance imaging, computerized tomography), home care, and palliative care.

\section{Collaboration in general clinical practice}

Regarding collaboration in general clinical practice, our respondents were asked whether they participated in an inter-professional collaborative practice, excluding the hospital environment and referrals. Nearly two-thirds of respondents $(n=67)$ indicated that they have interprofessional collaborative practice. Among the providers involved in collaborative teams, respondents were given a list of specialists (e.g., cardiologists, general internists,

Table 3 Patient visits

\begin{tabular}{lll}
\hline Category & $N$ & $\%^{\mathrm{a}}$ \\
\hline General Patient Visits & & \\
Urgent matter & 83 & 70.3 \\
$\quad$ Same day & 10 & 8.5 \\
$\quad$ First available, but not same day & 9 & 7.6 \\
Other & 3 & 2.5 \\
Unsure & & \\
Non-urgent matter & 66 & 55.9 \\
Same week & 23 & 19.5 \\
When available, but not same week & 9 & 7.6 \\
Other & 6 & 5.1 \\
$\quad$ Unsure
\end{tabular}

aPercentage calculated from overall sample 

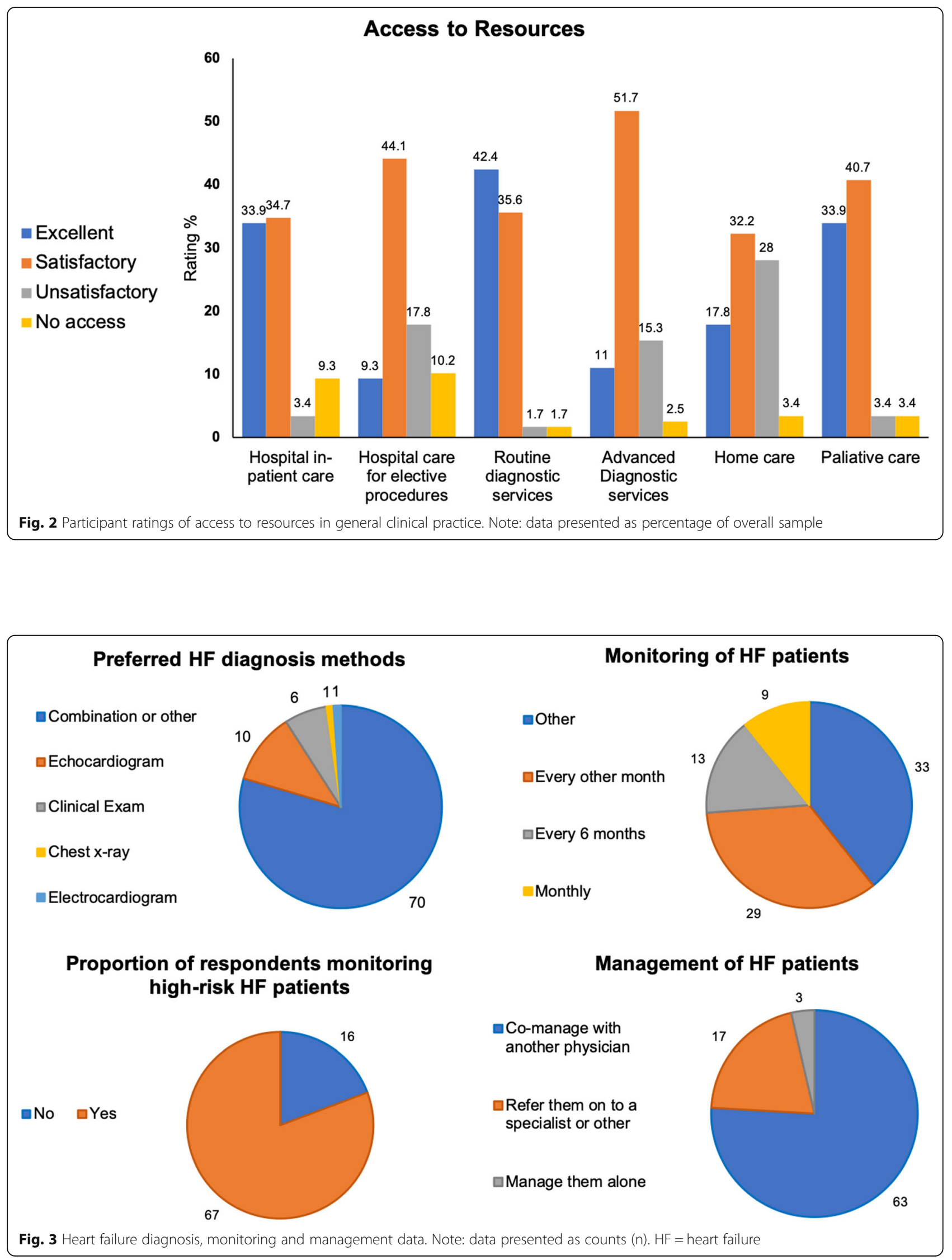
other physicians, psychiatrists etc.) and were asked to select the ones with whom they mostly collaborate. Our results indicate that other health care providers $(n=56$, e.g., nurse practitioners, physiotherapists, and occupational therapists), other physicians $(n=32$ e.g., family physicians, emergency medicine, geriatrics, palliative care, urologists) and psychiatrists $(n=23)$ were the most common professionals involved in the inter-profession collaborative practice, followed by general internal medicine $(n=11)$, cardiologists $(n=9)$, obstetricians/gynecologists $(n=8)$, orthopedic surgeons $(n=5)$, general surgeons $(n=4)$ and dermatologists $(n=2)$.

\section{Heart failure management}

Regarding HF patients, our respondents indicated seeing on average 20 patients $(\mathrm{IQR}=34)$ per week. When asked about means to identify/diagnose HF patients in their practice, most respondents reported using a combination of methods/techniques ( $n=70$, e.g., combination of electrocardiogram, echocardiogram, and chest $\mathrm{x}$-ray), while others reported using solely echocardiogram $(n=10)$, please see Fig. 3 for details. Additionally, other respondents also indicated using clinical exam and medical history in their diagnostic process. Furthermore, onequarter of respondents $(n=29)$ indicated monitoring their HF patients every 6 months; however, the majority of respondents $(n=33)$ reported doing so in a timeline other than provided in the survey. This second group indicated seeing patients approximately every 3 months on average $(n=18)$, and that monitoring would be heavily influenced by the patient's medical condition (e.g., 15 respondents indicated that number and frequency of visits would increase with worsening of patient's health).
Accordingly, most respondents reported $(n=67)$ having high-risk patients in their practice, with an estimated number of high-risk patients ranging from 1 to 50 per practice.

Respondents in our study also reported co-managing their HF patients with another physician $(n=63)$, while some would rather refer these patients on to a specialist or others $(n=17$; others included respiratory therapist and certified educator for HF education program), with a minority of physicians preferring to manage patients alone $(n=3)$. Respondents' choices for co-managing patients with other physicians are shown in as show in Table 4, stratified by respondent's health care professional category (e.g., family physician, resident etc.). When asked whether they managed HF patients differently from patients with other chronic health conditions (e.g., diabetes), most responded $(n=50)$ no differences in management, while other respondents $(n=33)$ indicated managing differently. Further, when probed regarding how respondents manage HF patients compared to other chronic health conditions, the majority of survey respondents indicated that their HF patients would need more co-management, more office visits, and more urgent visits.

As well, the extreme majority of individuals $(n=80)$ in this survey suggested they would like to manage their HF patients as part of a team, particularly in comanagement $(n=78)$; and 47 respondents reported that they are currently satisfied with the way they management HF patients (family physicians $=32$; residents $=8$; specialist $=1$; and other health care providers $=6$ ); others $(n=36)$ suggested that there are limitations preventing them from managing patients the way they would like.

Table 4 Heart failure management

\begin{tabular}{|c|c|c|c|c|c|c|}
\hline Category $^{a}$ & Family Physician & Resident & Specialist & Internist & Other HCP & Total \\
\hline HF Management & $60(50.8)$ & $13(11)$ & $2(1.7)$ & $1(0.8)$ & $7(5.9)$ & $83(70.3)$ \\
\hline Co-manage with another physician & $47(39.8)$ & $8(6.8)$ & $2(1.7)$ & $1(0.8)$ & $5(4.2)$ & $63(53.4)$ \\
\hline Refer patients to specialist or other & $10(8.5)$ & $5(4.2)$ & - & - & $2(1.7)$ & $17(14.4)$ \\
\hline Manage patients alone & $3(2.5)$ & - & - & - & - & $3(2.5)$ \\
\hline \multicolumn{7}{|l|}{ HF Co-Management ${ }^{\mathrm{b}}$} \\
\hline Cardiologist alone & $23(19.5)$ & $2(1.7)$ & $1(0.8)$ & - & - & $26(22)$ \\
\hline Internist alone & $8(6.7)$ & $1(0.8)$ & - & - & $2(1.7)$ & $11(9.3)$ \\
\hline Other Family Physician alone & $1(0.8)$ & $1(0.8)$ & - & $1(0.8)$ & $1(0.8)$ & $4(3.4)$ \\
\hline Cardiologist and Internist & $13(11)$ & $2(1.7)$ & - & - & - & $15(12.7)$ \\
\hline Cardiologist and other Family Physician & $1(0.8)$ & $1(0.8)$ & - & - & $1(0.8)$ & $3(2.5)$ \\
\hline Cardiologist, Internist and other Family Physician & $1(0.8)$ & - & - & - & $1(0.8)$ & $2(1.7)$ \\
\hline Others $^{c}$ & - & $1(0.8)$ & $1(0.8)$ & - & - & $2(1.7)$ \\
\hline
\end{tabular}

Bold numbers indicate total number of respondents per HCP category $H C P$ Health care professionals, $H F$ heart failure

${ }^{a}$ Data reported as number and percentage derived from all initial survey respondents $(n=118)$

${ }^{\mathrm{b}}$ For respondents who reported co-managing patients with another physician

${ }^{\mathrm{C}} \mathrm{A}$ participant reported co-managing with a nephrologist, while other with nurse practitioner 
Table 5 Limitations preventing management of heart failure patients

\begin{tabular}{|c|c|c|c|c|c|c|}
\hline Category $^{a}$ & Family Physician & Resident & Specialist & Internist & Other HCP & Total \\
\hline Lacking Experience & $11(9.3)$ & $3(2.5)$ & - & - & $1(0.8)$ & $15(12.7)$ \\
\hline HF Guidelines & $9(7.6)$ & $1(0.8)$ & - & - & $1(0.8)$ & $11(9.3)$ \\
\hline Current drug therapy & $9(7.6)$ & $1(0.8)$ & - & - & $1(0.8)$ & $11(9.3)$ \\
\hline Medication management for patients with HF and co-morbidities & $8(6.8)$ & $2(1.7)$ & - & - & $1(0.8)$ & $11(9.3)$ \\
\hline How to read test results & $5(4.2)$ & $1(0.8)$ & - & - & $1(0.8)$ & $7(5.9)$ \\
\hline Patient/family/caregiver education & $6(5.1)$ & $1(0.8)$ & - & - & $1(0.8)$ & $8(6.8)$ \\
\hline No limitations in experience category & $17(14.4)$ & $2(1.7)$ & $1(0.8)$ & $1(0.8)$ & - & $21(17.8)$ \\
\hline Lacking Education/Training & $9(7.6)$ & $3(2.5)$ & - & - & $1(0.8)$ & $13(11)$ \\
\hline HF Guidelines & $8(6.8)$ & $1(0.8)$ & - & - & - & $9(7.6)$ \\
\hline Current drug therapy & $7(5.9)$ & $1(0.8)$ & - & - & - & $8(6.8)$ \\
\hline Medication management for patients with HF and co-morbidities & $6(5.1)$ & $1(0.8)$ & - & - & $1(0.8)$ & $8(6.8)$ \\
\hline How to read test results & $5(4.2)$ & $1(0.8)$ & - & - & $1(0.8)$ & $7(5.9)$ \\
\hline Patient/family/caregiver education & $5(4.2)$ & - & - & - & - & $5(4.2)$ \\
\hline No limitations in education/training category & $19(16.1)$ & $2(1.7)$ & $1(0.8)$ & $1(0.8)$ & - & $23(19.5)$ \\
\hline Lacking Resources & $20(16.9)$ & $5(4.2)$ & - & $1(0.8)$ & $1(0.8)$ & 27 (22.9) \\
\hline Practice set up (i.e., availability of nurses and support staff) & $15(12.7)$ & $4(3.4)$ & - & $1(0.8)$ & $1(0.8)$ & $21(17.8)$ \\
\hline Communication resources (i.e., other doctors, specialists) & $12(10.2)$ & $2(1.7)$ & - & $1(0.8)$ & $1(0.8)$ & $16(13.6)$ \\
\hline Time & $11(9.3)$ & $3(2.5)$ & - & - & - & $14(11.9)$ \\
\hline Patient load & $4(3.4)$ & - & - & $1(0.8)$ & - & $5(4.2)$ \\
\hline Money & $1(0.8)$ & $1(0.8)$ & - & - & - & $2(1.7)$ \\
\hline No limitations in resources category & $8(6.8)$ & - & $1(0.8)$ & - & - & $9(7.6)$ \\
\hline Other & $11(9.3)$ & - & $1(0.8)$ & - & - & $12(10.2)$ \\
\hline
\end{tabular}

Bold numbers indicate total number of respondents per HCP category HCP Health care professionals, HF heart failure

${ }^{\mathrm{a}}$ Data reported as number and percentage derived from all initial survey respondents $(n=118)$

For these latter respondents, we further requested they specify these possible limitations, results are shown in Table 5, stratified by respondent's health care professional category (e.g., family physician, resident etc.). Most respondents indicated that they would like to have access to more resources $(n=27)$, followed by more experience $(n=15)$ and lastly more education $(n=12)$ to manage HF patients in their practice. Finally, we inquired how respondents utilized the Ministry of Health and Long-Term Care (MOHLTC) Heart Failure Management Incentive fee code Q050A. Only $26.3 \%$ reported using the incentive $(n=31)$, while $29.7 \%$ indicated that they do not use it $(n=35)$, and $12.7 \%$ reported not being aware of the incentive $(n=15)$.

\section{Discussion}

\section{Main findings}

The current challenges to provide optimum care for patients with HF affect not only the patients themselves, but extends to their families, caregivers, physicians and other health care professionals. With a growing number of newly diagnosed cases every year, the burden on all the sectors of the health care sector and society is inescapable. Even though current recommendations stipulate a multidisciplinary approach to HF management and care [7], it remains to be determined whether such strategies are currently taking place in primary care. For example, given the low utilization of a special HF fee code we observed, this would suggest that introducing such supportive funding investments require supportive Continuing Medical Education (CME) programming. The overall goal of this study was to assess how health care professionals manage HF in their clinical practice in Southwestern Ontario, as well as, identify any perceived limitations, barriers and challenges in managing these patients.

We report that most of our respondents indicated participating in a collaborative practice setting, particularly with other health care professionals such as nurses and physiotherapists, as well as other family physicians. Similarly, despite nearly a third of respondents not having hospital privileges and practicing in rural areas, both of which could limit inter-professional collaboration, most respondents indicated co-managing their HF patients with other health care professionals, including cardiologist and internists. Co-management seems to be greatly 
valued in this context, since the vast majority of respondents reported preferring to manage their HF patients as part of a team rather than alone. This is an important pillar/component of the chronic care model (CCM) proposed by Wagner and colleagues [10, 11]. The development of collaborative and productive relationships between health care professionals is emphasized in this model. The model pertains to multidimensional approach to care, strengthening the relationships between health care providers, patients and their family, as well as integrating public and private resources in the community to aid in the daily management of chronic conditions. This model was not fully explored here but could benefit from future research in the management of $\mathrm{HF}$ patients.

Most of our respondents indicated being satisfied with the way they currently manage their HF patients, however, others indicated otherwise. The main limitation affecting this issue seemed to be related to practice set up (i.e., availability of nurses and support staff) and communication resources (i.e., with other doctors and specialists), followed by experience and education relating to HF guidelines, current drug therapy and medical management. Although we did not perform any inferential statistical test for this particular report, it is possible to consider that some of these factors might well be associated and even influenced by other factors, such as practice location (rural versus urban) especially in regards to greater or easier access to resources. Moreover, academic background, year of graduation, presence (or not) of a post-graduation degree, and hospital privileges might play important roles in suboptimal levels of satisfaction relating to how respondents in our survey manage their HF patients. One could consider that investing in CME specifically in HF management, would aid in addressing some of the main limitations indicated by our survey respondents. This could also aid in higher utilization of the HF fee code, as mentioned earlier. These observations, however, remain only as speculative.

\section{Limitations}

Our survey was designed based on previous knowledge gathered from literature review and was critically appraised by experts in the field, however, it is not without limitations. One of the main constraints of the online survey is that we could not ensure that all respondents completed the survey thoroughly, with only two-thirds of respondents completing all questions in the questionnaire $(n=80)$; however, $96(81 \%)$ respondents completed at least half of the survey. This does not particularly invalidate the data collected; however, it could bias our results by reflecting only the answers of those who completed the questionnaire. We also report results from a diverse group including individuals with different needs (e.g., senior doctors vs residents). In addition, although we attempted to design a relatively short survey, we appreciate many respondents may have not completed the survey due to time constraint. Further, due to a small sample size, we analyzed our data summarizing information across all different individuals who took the survey, however the majority of the respondents were either family physicians or family medicine residents; therefore, our results may not generalize outside the context of our sample in this study. As well, our sample of respondents were from Southwestern Ontario only and may not reflect practice and challenges in other parts of the province, particularly because the prevalence of heart disease in Southwestern Ontario is higher than in other parts of the province [12], even though distribution of physicians is similar across regions, as well as the prevalence of other chronic conditions such as diabetes and chronic obstructive pulmonary disease $[12,13]$. Finally, due to the nature of the data collected, we are not able to perform hypothesis testing to confirm our speculations.

\section{Conclusions}

Health care professionals involved in HF management, including family physicians, specialists, nurses, allied health professionals and family medicine residents were surveyed in this study. Our main findings indicate that these professionals are involved in collaborative HF management and prefer to co-manage their patients in multidisciplinary teams. Most respondents reported being satisfied with the current way in which they manage their HF patients. For those who reported being currently unsatisfied, the main factors that could be considered barriers and/or limitations were to access to resources, especially practice set up and communication with other health care professionals, as well as limitations with education and experience in regard to HF guidelines, current drug therapy and medical management. Future research should consider these factors in developing strategies to enhance primary care for HF patients especially with regards to managing these patients in collaborative and multidisciplinary system of care. The identification of and characterisation of subgroups facing these barriers and/or limitations in their practice would facilitate targeted intervention aiming at counteracting these items.

\section{Abbreviations}

HF: Heart failure; IQR: Interquartile range; MOHLTC: Ministry of Health and Long-Term Care

Acknowledgments

We would like to thank all respondents for taking part in this survey. 


\section{Authors' contributions}

RWP and RJP designed the study, developed the online survey, appraised the manuscript for critical review and approval. NCBSS performed statistical analysis and drafted the manuscript. DL reviewed and approved the manuscript. RJP was the primary investigator in the study. All authors have read and approved the manuscript.

\section{Funding}

This study was funded by the Ontario Strategy for Patient-Oriented Research (SPOR) Support Unit and a Foundation Grant from the Canadian Institutes of Health Research (CIHR) grant FDN 148446. Dr. Lee is supported by a midcareer investigator award from the Heart and Stroke Foundation and is the Ted Rogers Chair in Heart Function Outcomes, a joint Hospital-University Chair of the University Health Network and the University of Toronto. The funders were not involved in the study design, collection of data, analysis, interpretation of data or in writing the manuscript.

\section{Availability of data and materials}

The datasets used and/or analysed during the current study are available from the corresponding author upon request.

\section{Ethics approval and consent to participate}

This paper is the result of a Quality Improvement study conducted via an online survey and did not require formal ethics approval as per the 2014 TriCouncil Policy Statement: Ethical Conduct for Research Involving Humans, which states in Article 2.5 that quality improvement studies do not constitute research for the purposes of the Policy and not fall within the scope of a research ethics review board in Canada [14]. Survey respondents were informed that by answering the written online survey they would be providing consent to participate. Therefore, those who responded the online survey were considered to have consented to participate in the study.

\section{Consent for publication}

Not applicable.

\section{Competing interests}

The authors declare that they have no competing interests.

\section{Author details}

${ }^{1}$ Centre for Studies in Family Medicine, Department of Family Medicine, Schulich School of Medicine and Dentistry, Western University, London, ON, Canada. ${ }^{2}$ School of Kinesiology, Faculty of Health Sciences, Western University, London, ON, Canada. ${ }^{3}$ ICES, Toronto, ON, Canada. ${ }^{4}$ Peter Munk Cardiac Centre of the University Health Network, Division of Cardiology, University of Toronto, Toronto, ON, Canada. ${ }^{5}$ Department of Family Practice, Faculty of Medicine, University of British Columbia, Vancouver, BC, Canada. ${ }^{6}$ Western Centre for Public Health and Family Medicine, Western University, 2nd Floor, 1465 Richmond St, London, ON N6G 2M1, Canada.

Received: 22 May 2019 Accepted: 6 January 2020

Published online: 13 January 2020

\section{References}

1. Moayedi Y, Schofield T, Etchells E, Silver SA, Kobulnik J, McQuillan R, et al. Closing the care gap: a primer on quality improvement for heart failure clinicians. Circ Heart Fail. 2017;10(5):e003722.

2. Lee DS, Stukel TA, Austin PC, Alter DA, Schull MJ, You JJ, et al. Improved outcomes with early collaborative care of ambulatory heart failure patients discharged from the emergency department. Circulation. 2010;122(18): 1806-14 [cited 2019 Mar 27]. Available from: http://www.ncbi.nlm.nih.gov/ pubmed/20956211.

3. Heart and Stroke Foundation. 2016 report on the health of canadians: The burden of heart failure. Heart Stroke Found. 2016:1-12 [cited 2019 Mar 27]. Available from: https://www.heartandstroke.ca/-/media/pdf-files/canada/201 7-heart-month/heartandstroke-reportonhealth-2016.ashx?la=en\&hash=91 708486C1BC014E24AB4E719B47AEEB8C5EB93E.

4. Bergethon KE, Ju C, DeVore AD, Hardy NC, Fonarow GC, Yancy CW, et al. Trends in 30-day readmission rates for patients hospitalized with heart failure: findings from the get with the guidelines-heart failure registry. Circ Heart Fail. 2016;9(6):e002594.
5. Lee DS, Austin PC, Stukel TA, Alter DA, Chong A, Parker JD, et al. "Dosedependent" impact of recurrent cardiac events on mortality in patients with heart failure. Am J Med. 2009;122(2):162-169.e1.

6. Bradley EH, Curry L, Horwitz LI, Sipsma H, Wang Y, Walsh MN, et al. Hospital strategies associated with 30-day readmission rates for patients with heart failure. Circ Cardiovasc Qual Outcomes. 2013;6(4):444-50.

7. Panel P, Ezekowitz JA, Meara EO, Mcdonald MA, Abrams H, Chan M, et al. 2017 Comprehensive update of the canadian cardiovascular society guidelines for the management of heart failure. Can J Cardiol. 2017;33: 1342-433.

8. Ontario's Ministry of Health and Long-Term Care: Quality Improvement Plans. [cited 2019 Mar 28]. Available from: http://www.health.gov.on.ca/en/ pro/programs/ecfa/legislation/quality_improve.aspx. Accessed 28 Mar 2019.

9. The Leading Research \& Experience Software: Qualtrics. [cited 2019 Mar 28]. Available from: https://www.qualtrics.com/. Accessed 28 Mar 2019.

10. Bodenheimer T, Wagner EH, Grumbach K. Improving primary care for patients with chronic illness. J Am Med Assoc. 2002;288:1775-9.

11. Wagner EH, Glasgow RE, Davis C, Bonomi AE, Provost L, McCulloch D, et al. Quality improvement in chronic illness care: a collaborative approach. Jt Comm J Qual Improv. 2001;27(2):63-80.

12. Haq M, Numekevor L, Singh P, Chisholm A. Community health profile: Southwestern Ontario. 2016. Available from: http://www.swahn.ca/Uploads/ ContentDocuments/CC license Community Health Profile for Southwestern Ontario pdf

13. Pong RW, Pitblado JR. Geographic distribution of Physicians in Canada: beyond how many and where. Ottawa Can Inst Heal Inf. 2005;11 Available from: http://scholar.google.com/scholar?hl=en\&btnG=Search\&q=intitle: Geographic+Distribution+of+Physicians+in+Canada+:+Beyond+How+ Many+and+Where\#0.

14. Canadian Institutes of Health Research, Natural Sciences and Engineering Research Council of Canada, Social Sciences and Humanities Research Council of Canada. Tri-council policy statement: ethical conduct for research involving humans. 2014. Available from: http://www.pre.ethics.gc.ca/eng/ policy-politique/initiatives/tcps2-eptc2/Default/

\section{Publisher's Note}

Springer Nature remains neutral with regard to jurisdictional claims in published maps and institutional affiliations.

\section{Ready to submit your research? Choose BMC and benefit from:}

- fast, convenient online submission

- thorough peer review by experienced researchers in your field

- rapid publication on acceptance

- support for research data, including large and complex data types

- gold Open Access which fosters wider collaboration and increased citations

- maximum visibility for your research: over $100 \mathrm{M}$ website views per year

At BMC, research is always in progress.

Learn more biomedcentral.com/submissions 